\title{
Ten Years of Clinical Evaluation of the Woven EndoBridge: A Safe and Effective Treatment for Wide-Neck Bifurcation Aneurysms
}

\author{
Laurent Pierot, MD, PhD \\ Department of Neuroradiology, Hôpital Maison-Blanche, CHU Reims, University Reims-Champagne-Ardenne, Reims, France
}

\begin{abstract}
Intrasaccular flow disruption is an innovative approach for the endovascular treatment of intracranial aneurysms. As of now, only one device is currently available worldwide: the Woven EndoBridge (WEB) device (MicroVention, Aliso Viejo, CA, USA). After 10 years of clinical use and careful clinical evaluation of the WEB device by multiple prospective, multicenter studies, this article is summarizing the current knowledge regarding this endovascular technique; indications, modalities, safety and efficacy of the WEB procedure are described.
\end{abstract}

Key Words: Intracranial aneurysm; Endovascular technique; Device safety

For several years, endovascular therapy (EVT) has been the first line treatment for most intracranial aneurysms. ${ }^{1,2}$ Despite continued iterations of new devices and techniques, wide-necked bifurcation aneurysms (WNBAs) have remained a challenging cohort for existing endovascular treatment strategies., ${ }^{3,4}$ Intrasaccular flow disruption (IS-FD) is an innovative approach that involves placing a self-expanding, cage-like device within the aneurysm. ${ }^{5-10}$ Only one IS-FD device - the Woven EndoBridge (WEB MicroVention, Aliso Viejo, (A, USA) - is currently commercially available worldwide. It has been extensively evaluated in a series of high quality, prospective trials conducted in Europe (WEB Clinical Assessment of Intrasaccular Aneurysm
Therapy [WEBCAST] and WEBCAST-2), in the USA (WEB Intrasaccular Therapy [WEB-IT]), and in France (French Observatory). ${ }^{11-17}$ Additional WEB trials are currently recruiting or under analysis: CLinical Assessment of WEB ${ }^{\circledR}$ Device in Ruptured aneurYSms (CLARYS), CLinical EValuation of WEB 0.017 Device in Intracranial AneuRysms (CLEVER), and WEB ${ }^{\oplus}$ IT China (WEB-IT China).

Now that IS-FD with WEB has been used in clinical practice in Europe for 10 years, this review analyzes the technical evolution, place, indications, safety and efficacy of IS-FD with WEB, as well as the practical use of the WEB device including complications and their management.

\section{Correspondence to:} Laurent Pierot, MD, PhD

Department of Neuroradiology, Hôpital Maison-Blanche, CHU Reims, 45 rue Cognacq-Jay, 51092 Reims cedex, France

Tel: +33326788764

Fax: +33326787594

E-mail: Ipierot@gmail.com

Received: August 25, 2021

Revised: October 4, 2021

Accepted: October 11, 2021

Copyright $\odot 2021$ Korean Society of Interventional Neuroradiology

This is an Open Access article distributed under the terms of the Creative Commons Attribution Non-Commercial License (http://creativecommons.org/licenses/by-nc/4.0) which permits unrestricted non-commercial use, distribution, and reproduction in any medium, provided the original work is properly cited.

pISSN 2093-9043 eISSN 2233-6273 


\section{WEB TECHNOLOGY: DESCRIPTION AND EVOLUTION}

The WEB is a self-expanding, retrievable, electrothermally detachable, nitinol-braided device, which is placed within the aneurysm sac. The device disrupts blood flow at the aneurysm neck and induces intra-aneurysmal thrombosis. On the contrary to the irregular surface created by the coils at the level of the neck, WEB is offering a flat proximal surface that is potentially a better support for neoendothelium. Preliminary evaluation in an in vivo animal aneurysm model showed promising rates of immediate and long-term aneurysm occlusion. $^{18}$

Since its initial introduction in European clinical practice in 2010, the device has evolved through several iterations: the WEB dual layer (WEB DL) was initially introduced, followed by single layer in two shapes (barrel: WEB SL, and spherical: WEB $S L S)$, which evolved into a version that enhanced visualization (WEB SL EV and WEB SLS EV) by incorporating composite wire strands made from nitinol and platinum.

In tandem with device developments and the platform's optimization, the microcatheters used to deliver these devices also evolved. Initially, the WEB DL was delivered using Headway 27 (MicroVention) or DAC 038 (Stryker Neurovascular, Fremont, CA, USA) according to the device size. Later, specific microcatheters were developed for WEB treatment including the VIA 21, VIA 27, and VIA 33 (MicroVention). Recently, the 17 microcatheters (MicroVention) was introduced for WEB sizes between 3-7 mm in straight and pre-shaped versions.

\section{THE ROLE OF THE WEB FOR TREATING INTRACRANIAL ANEURYSMS}

\section{Indications}

The WEB was initially designed to treat WNBAs arising at the proximal bifurcations, including the internal carotid artery terminus (ICAt), basilar artery (BA), anterior communicating artery (Acom), and middle cerebral artery (MCA) (Fig. 1). The WEB device was approved by US Food and Drug Administration (December 31, 2018) for use in adults to embolized saccular intracranial wide neck bifurcation aneurysms located in the anterior (MCA bifurcation, ICA terminus, Acom complex) and posterior (BA apex) circulations, ranging in size from 3 $\mathrm{mm}$ to $10 \mathrm{~mm}$ in dome diameter, where the neck is $4 \mathrm{~mm}$ or greater or the dome-to-neck ration is greater than 1 and less than 2 .

The proportions of aneurysms in each of these treatment locations differ notably between Europe and the USA, which is related to differing roles of open surgery in managing intracranial aneurysms. ${ }^{15,16}$ In the three European studies, aneurysm locations were MCA in 50.9\%, Acom in 21.3\%, BA in $17.8 \%$, and ICAt in $10.1 \%{ }^{16}$ In the US Good Clinical Practice (GCP) study (WEB-IT), aneurysm locations were BA in 39.3\%, MCA in 30.0\%, Acom in 26.7\%, and ICAt in 6.4\%. ${ }^{17}$ The progressive improvement of the technology (dual-layer to single-layer devices, enhanced visualization, and reduced microcatheter size) has led to an expansion of potential clinical indications to more distal aneurysms (e.g., pericallosal) and sidewall aneurysms (e.g., carotid siphon) in Europe. 19,20

In contrast to intracranial microstents, the WEB is purely an intrasaccular device and does not require dual antiplatelet treatment (DAPT). As such, the WEB can be used to treat un-
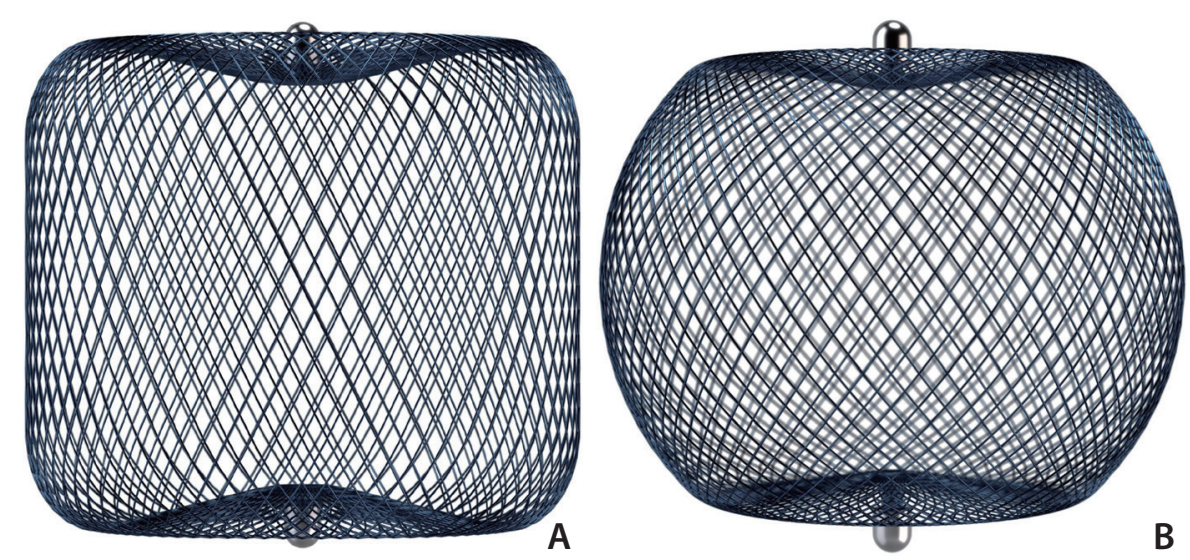

Fig. 1. WEB devices (MicroVention, Aliso Viejo, CA, USA). (A) WEB SL. (B) WEB SLS. WEB, Woven EndoBridge; SL, single layer; SLS, single layer spherical. 
ruptured and ruptured aneurysms. ${ }^{16,17,21-27}$ To date, the four European GCP studies and the USA have included a relatively small number of ruptured aneurysms: $6.0 \%$ in WEB-IT and 8.3\% in the three European GCP studies. ${ }^{16,17}$

Several series and meta-analyses have recently focused on ruptured aneurysm management with WEB, showing its good efficacy in preventing rebleeding (see below). ${ }^{21-27}$ In a recent meta-analysis, Essibayi et al. ${ }^{27}$ reported a rate of late rebleeding of $1.1 \%$. Yet, there have been very few studies analyzing the role of WEB treatment versus other EVT techniques when managing ruptured aneurysms. In a single-center series of 242 patients with ruptured aneurysms, EVT treated $78 \%$ of ruptured aneurysms, with WEB as the first-line EVT (52.9\% of the aneurysms undergoing EVT). ${ }^{22}$

There have also been very few studies regarding the role of the WEB device when managing unruptured aneurysms. In a single-center series that reported WEB as the first-line treatment for unruptured aneurysms, $75 \%$ of aneurysms were treated with WEB and $25 \%$ with coils. ${ }^{28}$

\section{SELECTION OF ANEURYSMS TO TREAT WITH WEB}

\section{Aneurysm Sizes}

Given currently available device sizes (from 3 to $11 \mathrm{~mm}$ in width), and the fact that oversizing devices in width is recommended, aneurysms ranging from 2 to $10 \mathrm{~mm}$ in size can potentially be treated with the WEB device.

\section{Aneurysm Shapes}

WEB devices are spherical (WEB SLS) or cylindral (WEB SL); thus, unilobular aneurysms with spherical, cylindral, or ovoid shape morphology are ideal candidates for WEB treatment. ${ }^{29}$ However, WNBAs with irregular multilobular morphology can also be treated with WEB by sizing the device to the primary lobe (the device will not occupy the secondary lobules). The treatment can be difficult when a daughter sac arises near the neck because covering it can result in parent artery WEB protrusion.

\section{Aneurysm Height Axis/Parent Artery Angle}

The initial recommendation was to use the WEB device in an angled aneurysm when the parent artery was less than $45^{\circ}$. Since device evolution has partially removed this limitation, aneurysms with a parent artery angle up to $90^{\circ}$ are now treatable, singularly with WEB-17. The recent addition of VIA $1745^{\circ}$ and $90^{\circ}$, and the possibility to steam-shape the VIA microcatheter, help to catheterize aneurysms with strong angulation and also deploy the WEB.

\section{Incorporated Vessels}

WNBAs often have arterial branches arising from the neck. In this situation, it often remains possible to treat these aneurysms with WEB by placing it distal to incorporated branches; however, this approach does risk a neck remnant. It can be useful to place a microcatheter or a remodeling balloon in the branch to protect it and also to place a stent in case of WEB protrusion.

\section{PERFORMING THE WEB PROCEDURE}

\section{Antiplatelet Treatment}

Ruptured aneurysms do not require pretreatment with antiplatelet medications. However, post-procedure, antiplatelet medications can be initiated, especially in case of WEB protrusion.

For unruptured aneurysms, pretreatment with DAPT is currently used when planning treatments that may involve adjunctive stents. Postoperatively, if no stent was placed and no WEB protrusion shows, the patient is typically treated with single antiplatelet medication (aspirin) for five to six weeks.

\section{Access System}

WEB aneurysm treatment can be performed through femoral or radial access.

Triaxial access (long introducer sheath, intermediate catheter, microcatheter) is recommended. There are a variety of intermediate catheters available that can be used including DAC 038 or 044 (Stryker Neurovascular) or SOFIA Plus (MicroVention). A VIA microcatheter should be used for WEB deployment and should be chosen in conjunction with selected WEB size (VIA 17 for WEB devices with a width between 3 and $7 \mathrm{~mm}$, VIA 27 for WEB devices with a width of 8 or $9 \mathrm{~mm}$, or VIA 33 for WEB devices with a width of 10 or $11 \mathrm{~mm}$ ). Manufacturers recommend steam-shaping the microcatheter to facilitate VIA navigation, optimize the distal tip position in the aneurysm sac, and facilitate the WEB's safe deployment. It is important to keep in mind that the VIA's very distal tip is not radiopaque for approximately $1 \mathrm{~mm}$. 

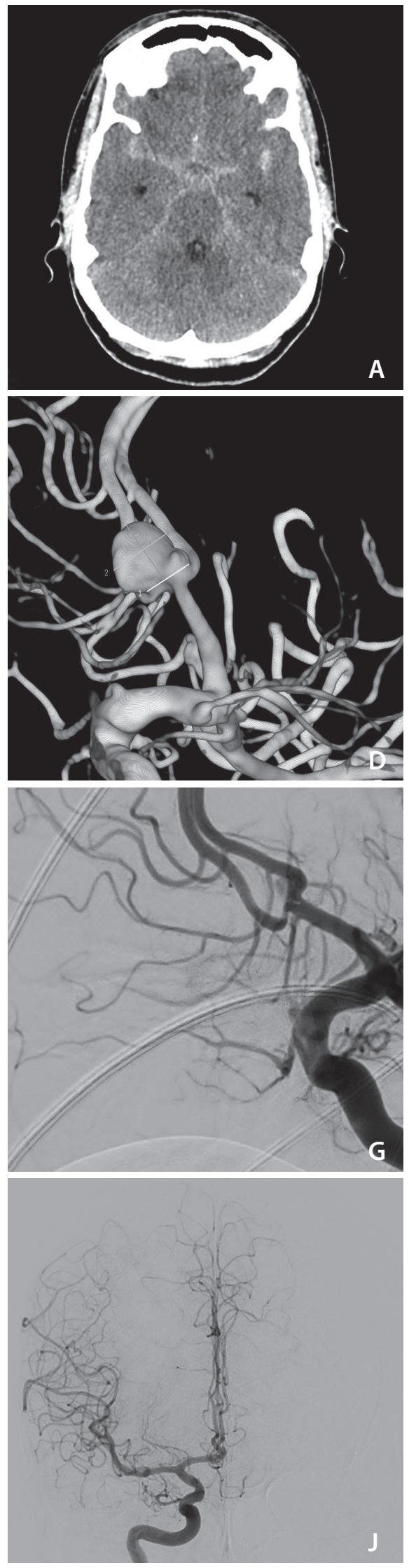
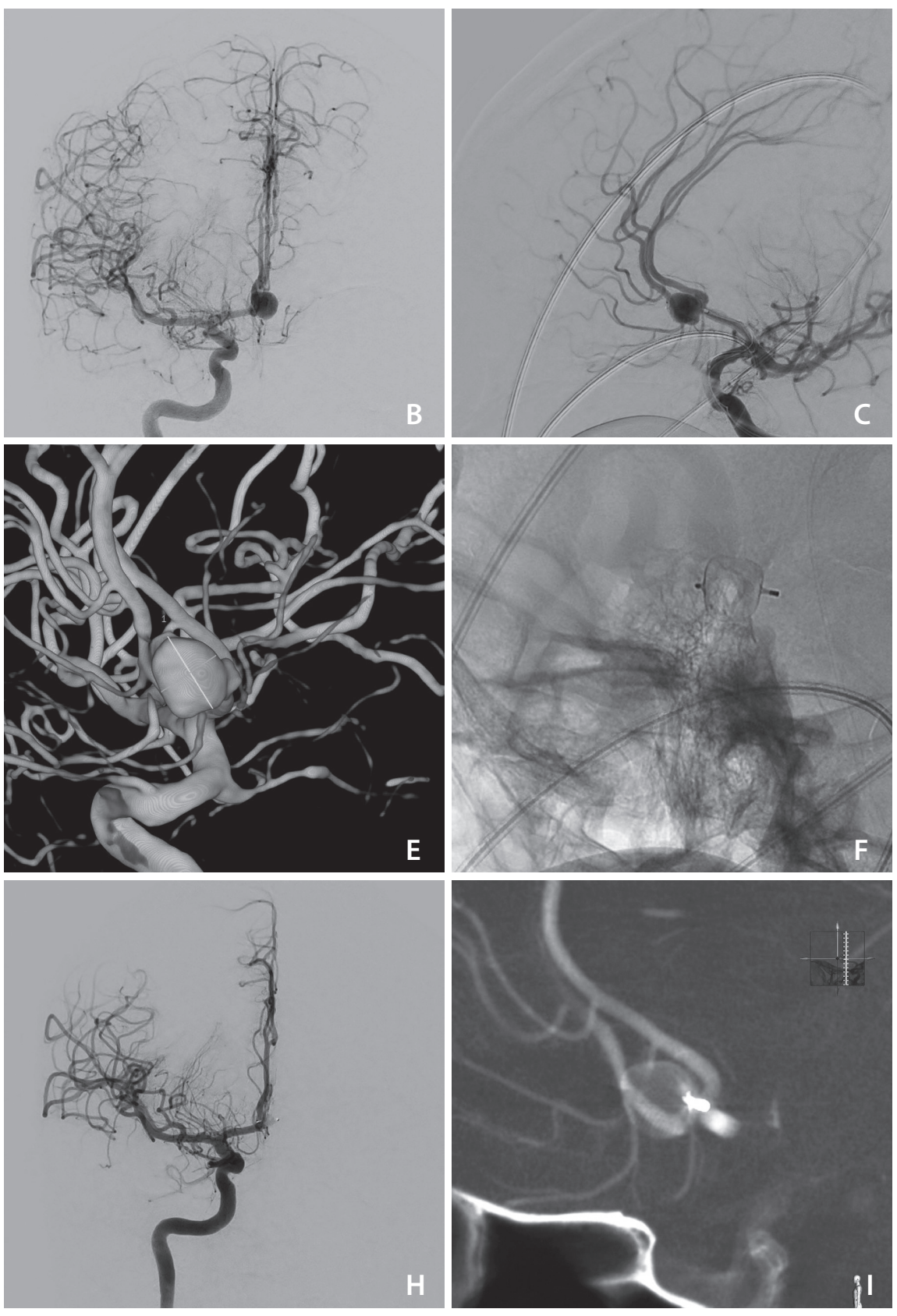

Fig. 2. Selection of the WEB device (MicroVention, Aliso Viejo, CA, USA): ruptured anterior communicating artery aneurysm (informed consent for publication was not obtained so we anonymized the patient). (A) Non-contrast head CT showing bilateral subarachnoid hemorrhage. (B) 2D-DSA, front view, showing an anterior communicating artery aneurysm. (C) 2D-DSA, working view, showing the aneurysm. (D) 3D-DSA: measurements are performed to select the WEB device. Neck: $5.7 \mathrm{~mm}$; width: $7.6 \mathrm{~mm}$; height: $7.3 \mathrm{~mm}$. (E) 3D-DSA, upper view of the dome. This view is very useful to measure the aneurysm width in 2 orthogonal directions: width 1: $9.0 \mathrm{~mm}$; width 2: $7.0 \mathrm{~mm}$. Mean width is $8 \mathrm{~mm}$. (F) According to aneurysm measurements (D, E), A WEB SL 9x4 $\mathrm{mm}$ is selected. The device is oversized in width $1 \mathrm{~mm}$ and undersized in height $3 \mathrm{~mm}$. (G) DSA, working view, after WEB detachment, showing complete aneurysm occlusion. (H) DSA, front view, after WEB detachment, showing complete aneurysm occlusion. (I) Flat-panel CT showing the WEB position in the aneurysm sac. (J) 1-year DSA showing complete aneurysm occlusion. WEB, Woven EndoBridge; CT, Computed Tomography; DSA, Digital Subtraction Angiography. 


\section{Device Selection}

Currently, two device shapes are available (see above): WEB SLS is designed for treatment of spherical or ovoid shape aneurysms, while WEB SL is designed to treat more cylindral bifurcation aneurysms (Fig. 1). ${ }^{29}$

Appropriate device sizing is crucial for successful treatment (Fig. 2). Using 2D and 3D digital subtraction angiography (DSA) images, aneurysm measurement of the sac and neck width in two orthogonal projections must be performed. Device width has to be oversized by 1 to $2 \mathrm{~mm}$ compared to aneurysm mean width ( $1 \mathrm{~mm}$ for small aneurysms and $2 \mathrm{~mm}$ for larger aneurysms). Oversizing the device allows to have it laterally compressed in order to have it fully applied against the aneurysm wall. It can result in slight lengthening which demands that the device height be reduced by at least $1 \mathrm{~mm}$ in order to avoid device protrusion. Importantly, it is not necessary to have the WEB device completely fill the aneurysm dome because a rapid thrombosis occurs at this level. If the device is properly oversized, it will compress laterally and lengthen on its main axis. Device position can be evaluated clearly by performing a flat panel cone beam computed tomography (CT).

The WEB device is fully retrievable once deployed, which means it can be exchanged for another shape or size if the original does not optimally fit the aneurysm sac. If the device is not sufficiently oversized, it will not be compressed laterally, which risks aneurysm recanalization. If the device is oversized too much, the risk of rupture is very low, but the main risk is protrusion in the bifurcation or its branches. For the vast majority of aneurysm morphologies, the manufacturer's sizing table outlining the oversizing rule of thumb is reliable and simple to use.

\section{WEB Deployment}

Deployment should be performed slowly when unsheathing and/or pushing the device. The device should not be pushed against the aneurysm wall to avoid potential perforation. Given that the device is relatively stiff at this stage, deployment of the device's first few millimeters is critical. Once the device begins to deploy, it blossoms and the risk of perforation decreases. At this stage, it is possible to change the device's shape and position in the aneurysm sac by pushing and tracking it. When the device is fully deployed, its position has to be monitored by performing 2D DSA or flat panel cone beam CT. If the aneurysm neck is completely sealed by the proximal surface of the device, the device is compressed laterally, and the proximal marker is in the neck or the bifurcation, the device position is satisfactory.

\section{WEB Detachment}

WEB devices detach using an electrothermal mechanism, usually on a blank roadmap that permits visualization of a slight movement of the proximal marker band which confirms proper detachment. After the device detaches, control DSA must be performed to check that the WEB position remains unchanged and appropriate.

\section{Additional Devices}

The WEB device is a standalone treatment for intracranial aneurysms. However, additional devices can sometimes be fruitfully used in combination with the WEB device.

- Coils: Coils are rarely used in combination with the WEB device. The main indication is when an aneurysm remnant is depicted after WEB detachement, meaning that the WEB was not properly oversized. In this case, additional coils can be placed in the remnant.

- Remodeling balloon: When it is difficult to properly place the WEB in the aneurysm and singularly when it is partially bulging in one of the bifurcation branches, it can be useful to place, before WEB deployment, a balIoon in the branch. Its inflation will permit to modify the position of the WEB. ${ }^{30}$ Using a remodling after full WEB deployment is less efficacious.

- Stent: Additional stenting is performed when a branch is arising from the neck and the WEB can potentially protrude in it. In that case microcatheter is placed in the branch before WEB deployment, the WEB is deployed, and the stent is deployed at the end of the procedure if needed. ${ }^{31}$ A stent can also be used in case of WEB protusion to preserve branch permeability. ${ }^{31}$

- Flow diverter: As WEB and flow diverters have relatively similar mechanism of action, there is no clear rationale to associate them.

\section{WEB TREATMENT SAFETY}

\section{Complications}

The three European studies (WEBCAST, WEBCAST-2, and French Observatory) analyzed the cumulative rate perioperative complications. ${ }^{16}$ The rate of hemorrhagic complications was $1.8 \%$ (3/167 patients) with two intraoperative aneurysm 
ruptures and one delayed (28 hours) intracranial hematoma related to DAPT. In all cases, no clinical worsening was observed. Intraoperative rupture is usually related to microguidewire or microcatheter manipulations in the aneurysm sac or to the initial WEB deployment in the sac: it is rarely a result of device oversizing (see above). Management of aneurysm rupture during WEB procedures includes the usual measures (discontinuation and reversal of heparin and balloon inflation in front of the neck) and quick deployment of the WEB in the aneurysm sac, which rapidly (a few seconds or minutes) stops the bleeding.

The rate of thromboembolic events as reported in the European series is $14.4 \%$ (24/167). While most events were not associated with clinical worsening $(6.6 \%, 11 / 167)$, some were associated with transient deficit $(4.8 \%, 8 / 167)$. Only 3.0\% (5/167 patients) experienced permanent deficit. Some thromboembolic events are related to WEB protrusion in the bifurcation or one branch of the bifurcation. When a WEB protrusion occurs, it can be useful to completely retrieve the device and initiate a new deployment (potentially under the cover of a remodeling balloon) in order to obtain a better WEB position. Alternatively, it is possible to place a stent in front of the WEB protrusion to keep the bifurcation and the branches open. When thromboembolic events are not related to WEB protrusion, the usual treatments are implemented: intra-arterial administration of antiplatelet medication and thrombectomy by aspiration or stentretriever.

\section{Morbidity and Mortality}

To date, WEB treatment has been associated with an extremely high level of procedural safety, which has been consistently observed in all existing prospective trials. In the cumulative population of the three European GCP studies (168 patients/169 aneurysms), the mortality at 1 month was $0.0 \%$ with morbidity $3.0 \%$ (5/168 patients). ${ }^{16}$ Morbidity was related to initial subarachnoid hemorrhage in $1.2 \%(2 / 168)$, to thromboembolic events in $1.2 \%$ (2/168), and to brainstem compression in $0.6 \%(1 / 168)$. Very similar results were reported in the US WEB-IT trial with a 1-month mortality of $0.0 \%$ and morbidity of $0.7 \%{ }^{17}$

Data on mid- and long-term follow-up (1, 2, and 3 years) have been provided by the European series. ${ }^{16,32,33}$ At 1 year, mortality was 3.3\% (5/153 patients) with 1.3\% (2/153 patients) related to WEB procedure (brainstem compression and retroperitoneal hematoma), while 2.0\% (3/153 patients) were unrelated to WEB procedure (cancer, cirrhosis). There was no morbidity between 1 year and 2 years leading to a 2-year morbidity rate of $1.4 \%$ (2/138 patients). Mortality at 2 years was 5.1\% (7/138 patients) with two additional deaths unrelated to WEB procedure (pneumonia, cancer). At 3 years, follow-up of participants in WEBCAST and WEBCAST-2 studies showed no delayed complications, a morbidity of 1.3\% (1/79 patients) unrelated to WEB procedure, and a mortality of $6.3 \%$ (5/79 patients) including 1.3\% related to the initial procedure.

These data confirm the exceptional safety of WEB treatment (which compares very favorably with other EVT results) (Table 1) with event rates that are very similar to standard coiling or superior to both stent-assisted coiling and intra-vascular flow diversion.

\section{WEB TREATMENT EFFICACY}

\section{Protection Against Rebleeding in Ruptured Aneurysms}

With a rate of $0.0 \%$ in most series, results have shown the WEB device's high efficacy in preventing early rebleeding. ${ }^{21-24}$

Table 1. Safety comparison of different endovascular techniques for intracranial aneurysm treatment

\begin{tabular}{lccc}
\hline Reference & $\begin{array}{c}\text { Aneurysm } \\
\text { status }\end{array}$ & Morbidity & Mortality \\
\hline Coiling & & & \\
ATENA $(2008)^{1}$ & UnR & $1.7 \%$ & $1.4 \%$ \\
HELPS $(2008)^{46}$ & UnR/R & - & $0.8 \%$ \\
CLARITY $(2011)^{2}$ & R & $3.7 \%$ & $1.7 \%$ \\
GREAT $(2017)^{47}$ & UnR/R & - & $2.1 \%{ }^{\dagger}$ \\
Stent-assisted coiling & & & \\
Piotin $(2010)^{48}$ & UnR/R & $7.4 \%$ & $4.6 \%$ \\
MAPS $(2014)^{49}$ & UnR/R & $1.6 \%$ & $2.3 \%$ \\
Phan $(2016)^{50}$ & UnR/R & - & $1.4 \%$ \\
Intra-vascular flow diversion & & & \\
PUFS $(2013)^{51}$ & UnR & $4.7 \%$ & $0.9 \%$ \\
Brinjikji $(2013)^{52}$ & UnR/R & $5.0 \%$ & $4.0 \%$ \\
Kallmes $(2016)^{53}$ & UnR/R & $5.7 \%$ & $3.3 \%$ \\
SAFE $(2018)^{54}$ & UnR & $2.0 \%$ & $1.0 \%$ \\
Intra-saccular flow disruption & & & \\
Pierot $(2017)^{16}$ & UnR/R & $3.0 \%$ & $0.0 \%$ \\
Fiorella $(2017)^{17}$ & UnR/R & $0.7 \%$ & $0.0 \%$ \\
\hline UnR unruptured; & &
\end{tabular}

UnR, unruptured; $R$, ruptured.

${ }^{*}$ Procedure-related. ${ }^{\dagger}$ Global. 
In the Crinnion et al. ${ }^{25}$ literature review, the rerupture rate after WEB treatment of ruptured aneurysms in 247 patients was $1.2 \%$ (the follow-up period was not specified). In the Harker et al. ${ }^{24}$ meta-analysis (309 WEB treatments), the rate of rebleeding was $2.5 \%$. In the CLARYS analysis at 1-month follow-up, the rate of rebleeding was $0.0 \%{ }^{26}$ In a recent meta-analysis, Essibayi et al. ${ }^{27}$ reported a 1.1\% rate of late rebleeding. In ISAT, the rebleeding rate after the procedure to 1 year was 3.2\% after coiling (2.5\% excluding patients who did not receive coils) and $1.3 \%$ after surgery. ${ }^{34}$ Therefore, the protection afforded by the WEB device against rebleeding is at least as good as coiling and also close to that of surgical procedures.

\section{Imaging Follow-up Modalities and Timing}

Follow-up timing is similar to what is performed for patients treated with flow diverters. A first imaging follow-up is performed at 3 to 6 months followed by a second one at 12 to 18 months. Timing of further follow-up is based on the initial $3 / 6$ months and 12/18 months findings.

The gold standard imaging for the follow-up of patients with aneurysms treated with WEB is DSA. Magnetic resonance angiography is also a useful tool knowing that residual flow inside the WEB device can be underestimated. ${ }^{35} \mathrm{CT}$ angiography can also be used. ${ }^{36}$

\section{Aneurysm Occlusion at Mid- and Long-Term}

In the cumulative population of the three European studies, anatomical results at 1 year were complete occlusion in $52.9 \%$ (81/153 aneurysms), neck remnant in 26.1\% (40/153 aneurysms), and aneurysm remnant in 20.9\% (32/153 aneurysms). ${ }^{16}$ The rate of adequate occlusion (complete occlusion or neck remnant) was $79.1 \%$. Similar results were reported in WEB-IT with complete aneurysm occlusion at 1 year in $53.8 \%$ and adequate occlusion in $84.6 \%{ }^{37}$

At 2-year follow-up, anatomical results were complete aneurysm occlusion in 51.2\% (62/121 aneurysms), neck remnant in 29.8\% (36/121 aneurysms), and aneurysm remnant in 19.0\% (23/121 aneurysms) with adequate occlusion in $81.0 \%{ }^{32}$

At 3-year follow-up, anatomical results were complete aneurysm occlusion in 50.8\% (31/61 aneurysms), neck remnant in 32.8\% (20/61 aneurysms), and aneurysm remnant in 16.4\% (10/61 aneurysms) with adequate occlusion in $83.6 \%{ }^{33}$

A direct comparison of effectiveness when compared to other endovascular aneurysm therapies (Table 2) is challenging given that the different technologies frequently address different target populations. The current impression is that IS-FD is less effective than intra-vascular flow diversion (IV-FD). However, in contrast to unruptured sidewall aneurysms treatment, the effectiveness of IV-FD for the treatment of bifurcation aneurysms remains a matter of significant debate and skepticism. Compared to traditional coil embolization, IS-FD appears to have a higher efficacy in terms of achieving complete or adequate occlusion of WNBAs, recognizing that most series reporting on coil embolization treat a variety of sidewall and bifurcation aneurysms as well as narrow and wide-necked aneurysms (Table 2).

\section{Retreatment}

The cumulative rate of aneurysm retreatment after initial WEB treatment has been evaluated in the European series and was $6.9 \%$ at 1 year, $9.3 \%$ at 2 years, and $11.4 \%$ at 3 years. ${ }^{16,32,33}$ The rate of retreatment at 1 year in WEB-IT was similar (5.6\%). Several endovascular retreatment modalities after initial WEB treatment have been reported in the literature, including stent-assisted coiling, stenting alone, flow diversion, and WEB with or without stent. ${ }^{16,37,38}$ Retreatment with clipping was

Table 2. Comparison of efficacy (anatomical results at 6-18 months) of different endovascular techniques for intracranial aneurysm treatment

\begin{tabular}{|c|c|c|c|}
\hline Reference & $\begin{array}{c}\text { Aneurysm } \\
\text { status }\end{array}$ & $\begin{array}{l}\text { Complete } \\
\text { occlusion }\end{array}$ & $\begin{array}{l}\text { Adequate } \\
\text { occlusion }\end{array}$ \\
\hline \multicolumn{4}{|l|}{ Coiling } \\
\hline HELPS $(2008)^{46}$ & UnR/R & $47.6 \%$ & $85.5 \%$ \\
\hline CLARITY $(2011)^{2}$ & $\mathrm{R}$ & $34.4 \%$ & $80.4 \%$ \\
\hline MAPS $(2014)^{49^{*}}$ & UnR/R & $27.1 \%$ & $57.6 \%$ \\
\hline GREAT $(2017)^{47}$ & UnR/R & $52 \%$ & $75 \%$ \\
\hline \multicolumn{4}{|c|}{ Stent-assisted coiling } \\
\hline MAPS $(2014)^{49^{*}}$ & UnR/R & $45.7 \%$ & $62.8 \%$ \\
\hline \multicolumn{4}{|c|}{ Intra-vascular flow diversion } \\
\hline PUFS $(2013)^{51+}$ & UnR & $86.8 \% \%$ & $94.3 \%$ \\
\hline Brinjikji $(2013)^{52}$ & UnR/R & $76.0 \%$ & - \\
\hline Kallmes $(2016)^{53}$ & UnR/R & $85.5 \%$ & - \\
\hline SAFE $(2019)^{55}$ & UnR & $73.3 \%$ & $81.1 \%$ \\
\hline \multicolumn{4}{|c|}{ Intra-saccular flow disruption } \\
\hline Pierot $(2017)^{16}$ & UnR/R & $52.9 \%$ & $79.1 \%$ \\
\hline
\end{tabular}

For most series, anatomical results included the global aneurysm population. PUFS only included large and giant internal carotid artery aneurysms. MAPS results are for the wide neck aneurysm subgroup.

UnR, unruptured; R, ruptured.

*Procedure-related. ${ }^{\dagger}$ Global. 
also feasible in some cases. ${ }^{39}$

\section{WEB Shape Modification}

In 2015, Cognard and Janue $\left.\right|^{40}$ were the first to describe the phenomenon of WEB shape modification that appeared to be associated with aneurysm recanalization. In this small series of 14 patients, the phenomenon was observed in nine patients (64.3\%) and the authors suggested that this was related to WEB compression. In fact, this phenomenon is more likely to be multifactorial mixing compression and retraction. ${ }^{41}$ A series effectively showing that WEB shape modification was an early and progressive phenomenon suggested that it was more likely related to the aneurysm healing process than to aneurysm compression. ${ }^{42}$ In a larger series (39 patients), Herbreteau et al..$^{43}$ reported the phenomenon in $31.6 \%$ of patients and showed that anatomical results were not inferior in the event of WEB shape modification. Another larger study (63 aneurysms) showed that the frequency of WEB shape modification was higher at long-term follow-up (mean: 15.5 months) than at short-term follow-up (mean: 6.1 months): $47.8 \%$ and $39.6 \%$, respectively. ${ }^{44}$ This study also showed that the extent of WEB shape modification did not directly correlate with anatomical results and that an appropriate WEB oversizing strategy mitigated WEB shape modification and could lead to improved angiographic results. Another recent series (32 aneurysms) that defined WEB shape modification as any reduction in WEB device height greater than $5 \%$ reported the phenomenon in $90.6 \%$ of aneurysms. ${ }^{45-55} \mathrm{~A}$ stronger decrease in WEB height was associated with a longer time interval post intervention. At 1 year, the median height reduction was 19.2\%. Finally, the quality of aneurysm occlusion was not associated with WEB shape modification.

\section{THE FUTURE OF INTRASACCULAR FLOW DISRUPTION}

It is likely that the role of intra-saccular flow disrupters in intracranial aneurysm treatment will likely expand significantly in the future. Investigators have started to report the use of WEB beyond the traditional proximal bifurcation anatomy studied in the prospective trials, with successful applications reported in side-wall as well as more distal bifurcation aneurysms. ${ }^{19,20}$ Some clinicians currently use WEB as a first line EVT for all cerebral aneurysms (ruptured and unruptured), which are technically amenable to IS-FD. ${ }^{22,28}$ Additional studies (including comparative ones) are required to define WEB safety and effectiveness for these expanded indications and, importantly, to define the place of WEB versus coiling when managing ruptured aneurysms. Provided that these ongoing studies continue to confirm the safety and effectiveness of IS-FD to be equivalent or superior to existing endovascular treatment strategies, it seems logical to predict that this technically straightforward approach will replace standard coiling in an increasing number of cases.

\section{CONCLUSION}

Endovascular treatment of intracranial aneurysms with the WEB device is the most recent innovation in the field. This treatment has been carefully evaluated in several prospective, multicenter studies that have consistently shown excellent safety and good efficacy when compared to current endovascular therapies for similar aneurysms. Given the procedure's technically straightforward and efficient nature, moving forward there will very likely be a progressive expansion of indications for IS-FD therapies to the extent that they will ultimately replace standard coiling in an increasing number of cases.

\section{Fund}

The writing of this paper was supported by Microvention.

\section{Ethics Statement}

According to the paper category (review), no ethical approval was needed. Informed consent for publication was not obtained so we anonymized the patient.

\section{Conflicts of Interest}

LP is consultant for Balt, MicroVention, Perflow, Phenox, and Vesalio.

\section{ORCID}

Laurent Pierot: https://orcid.org/0000-0002-2523-4909

\section{REFERENCES}

1. Pierot L, Spelle L, Vitry F; ATENA Investigators. Immediate clinical outcome of patients harboring unruptured intracranial aneu- 
rysms treated by endovascular approach: results of the ATENA study. Stroke 2008:39:2497-2504

2. Cognard C, Pierot L, Anxionnat R, Ricolfi F; Clarity Study Group. Results of embolization used as the first treatment choice in a consecutive nonselected population of ruptured aneurysms: clinical results of the Clarity GDC study. Neurosurgery 2011;69:837-841; discussion 842

3. Pierot L, Wakhloo AK. Endovascular treatment of intracranial aneurysms: current status. Stroke 2013;44:2046-2054

4. Pierot L, Biondi A. Endovascular techniques for the management of wide-neck intracranial bifurcation aneurysms: a critical review of the literature. J Neuroradio/ 2016;43:167-175

5. Pierot L, Liebig T, Sychra V, Kadziolka K, Dorn F, Strasilla C, et al. Intrasaccular flow-disruption treatment of intracranial aneurysms: preliminary results of a multicenter clinical study. AJNR Am J Neuroradiol 2012;33:1232-1238

6. Pierot L, Klisch J, Cognard C, Szikora I, Mine B, Kadziolka K, et al. Endovascular WEB flow disruption in middle cerebral artery aneurysms: preliminary feasibility, clinical, and anatomical results in a multicenter study. Neurosurgery 2013;73:27-34; discussion 34-35

7. Lubicz B, Klisch J, Gauvrit JY, Szikora I, Leonardi M, Liebig T, et al. WEB-DL endovascular treatment of wide-neck bifurcation aneurysms: short- and midterm results in a European study. AJNR Am J Neuroradiol 2014;35:432-438

8. Mine B, Pierot L, Lubicz B. Intrasaccular flow-diversion for treatment of intracranial aneurysms: the Woven EndoBridge. Expert Rev Med Devices 2014;11:315-325

9. Papagiannaki C, Spelle L, Januel AC, Benaissa A, Gauvrit JY, Costalat $\mathrm{V}$, et al. WEB intrasaccular flow disruptor-prospective, multicenter experience in 83 patients with 85 aneurysms. AJNR Am J Neuroradiol 2014;35:2106-2111

10. Pierot L, Klisch J, Liebig T, Gauvrit JY, Leonardi M, Nuzzi NP, et al. WEB-DL endovascular treatment of wide-neck bifurcation aneurysms: long-term results in a European series. AJNR Am J Neuroradiol 2015;36:2314-2319

11. Pierot L, Moret J, Turjman F, Herbreteau D, Raoult H, Barreau X, et al. WEB treatment of intracranial aneurysms: feasibility, complications, and 1-month safety results with the WEB DL and WEB SL/SLS in the French observatory. AJNR Am J Neuroradiol 2015;36:922-927

12. Pierot L, Costalat V, Moret J, Szikora I, Klisch J, Herbreteau D, et al. Safety and efficacy of aneurysm treatment with WEB: results of the WEBCAST study. J Neurosurg 2016;124:1250-1256

13. Pierot L, Moret J, Turjman F, Herbreteau D, Raoult H, Barreau X, et al. WEB treatment of intracranial aneurysms: clinical and ana- tomic results in the French observatory. AJNR Am J Neuroradiol 2016;37:655-659

14. Pierot L, Spelle L, Molyneux A, Byrne J; WEBCAST and French Observatory Investigators. Clinical and anatomical follow-up in patients with aneurysms treated with the WEB device: 1-year follow-up report in the cumulated population of 2 prospective, multicenter series (WEBCAST and French observatory). Neurosurgery 2016;78:133-141

15. Pierot L, Gubucz I, Buhk JH, Holtmannspötter M, Herbreteau D, Stockx $L$, et al. Safety and efficacy of aneurysm treatment with the WEB: results of the WEBCAST 2 study. AJNR Am J Neuroradiol 2017;38:1151-1155

16. Pierot L, Moret J, Barreau X, Szikora I, Herbreteau D, Turjman F, et al. Safety and efficacy of aneurysm treatment with WEB in the cumulative population of three prospective, multicenter series. J Neurointerv Surg 2018;10:553-559

17. Fiorella D, Molyneux A, Coon A, Szikora I, Saatci I, Baltacioglu F, et al.; WEB-IT Study Investigators. Demographic, procedural and 30-day safety results from the WEB Intra-saccular Therapy study (WEB-IT). J Neurointerv Surg 2017;9:1191-1196

18. Ding YH, Lewis DA, Kadirvel R, Dai D, Kallmes DF. The Woven EndoBridge: a new aneurysm occlusion device. AJNR Am J Neuroradiol 2011;32:607-611

19. Pierot L, Biondi A, Narata AP, Mihalea C, Januel AC, Metaxas $G$, et al. Should indications for WEB aneurysm treatment be enlarged? Report of a series of 20 patients with aneurysms in "atypical" locations for WEB treatment. J Neuroradiol 2017:44:203-209

20. Zimmer S, Maus V, Maurer C, Berlis A, Weber W, Fischer S. Widening the indications for intrasaccular flow disruption: WEB 17 in the treatment of aneurysm locations different from those in the good clinical practice trials. AJNR Am J Neuroradiol 2021;42:524-529

21. Liebig T, Kabbasch C, Strasilla C, Berlis A, Weber W, Pierot L, et al. Intrasaccular flow disruption in acutely ruptured aneurysms: a multicenter retrospective review of the use of the WEB. AJNR Am J Neuroradiol 2015;36:1721-1727

22. van Rooij SBT, van Rooij WJ, Peluso JP, Sluzewski M, Bechan $\mathrm{RS}$, Kortman $\mathrm{HG}$, et al. WEB treatment of ruptured intracranial aneurysms: a single-center cohort of 100 patients. AJNR Am J Neuroradiol 2017;38:2282-2287

23. Da Ros V, Bozzi A, Comelli C, Semeraro V, Comelli S, Lucarelli N, et al. Ruptured intracranial aneurysms treated with Woven Endobridge intrasaccular flow disruptor: a multicenter experience. World Neurosurg 2019;122:e498-e505

24. Harker P, Regenhardt RW, Alotaibi NM, Vranic J, Robertson FC, 
Dmytriw AA, et al. The Woven EndoBridge device for ruptured intracranial aneurysms: international multicenter experience and updated meta-analysis. [published online ahead of print May 25, 2021] Neuroradiology 2021

25. Crinnion W, Bhogal P, Makalanda HLD, Wong K, Arthur A, Cognard C, et al. The Woven Endobridge as a treatment for acutely ruptured aneurysms: a review of the literature. Interv Neuroradio/ 2021;27:602-608

26. Spelle L, Herbreteau D, Caroff J, Barreau X, Ferré JC, Fiehler J, et al. CLinical assessment of WEB device in ruptured aneurYSms (CLARYS): results of 1-month and 1-year assessment of rebleeding protection and clinical safety in a multicenter study. [published online ahead of print Sep 7, 2021] J Neurointerv Surg 2021

27. Essibayi MA, Lanzino G, Brinjikji W. Safety and efficacy of the Woven EndoBridge device for treatment of ruptured intracranial aneurysms: a systematic review and meta-analysis. AJNR Am J Neuroradio/ 2021;42:1627-1632

28. van Rooij SB, van Rooij WJ, Peluso JP, Sluzewski M. The Woven EndoBridge (WEB) as primary treatment for unruptured intracranial aneurysms. Interv Neuroradio/ 2018;24:475-481

29. Goyal N, Hoit D, DiNitto J, Elijovich L, Fiorella D, Pierot L, et al. How to WEB: a practical review of methodology for the use of the Woven EndoBridge. J Neurointerv Surg 2020;12:512-520

30. Mihalea C, Escalard S, Caroff J, Ikka L, Rouchaud A, Da Ros V, et al. Balloon remodeling-assisted Woven EndoBridge technique: description and feasibility for complex bifurcation aneurysms. J Neurointerv Surg 2019;11:386-389

31. Sahnoun M, Soize S, Manceau PF, Gelmini C, Pierot L. Intracranial aneurysm treatment with WEB and adjunctive stent: preliminary evaluation in a single-center series. [published online ahead of print Mar 30, 2021] J Neurointerv Surg 2021

32. Pierot L, Moret J, Barreau X, Szikora I, Herbreteau D, Turjman F, et al. Aneurysm treatment with Woven EndoBridge in the cumulative population of 3 prospective, multicenter series: 2-year follow-up. Neurosurgery 2020;87:357-367

33. Pierot L, Szikora I, Barreau X, Holtmannspoetter M, Spelle L, Herbreteau $\mathrm{D}$, et al. Aneurysm treatment with WEB in the cumulative population of two prospective, multicenter series: 3-year follow-up. J Neurointerv Surg 2021;13:363-368

34. Molyneux A, Kerr R, Stratton I, Sandercock P, Clarke M, Shrimpton J, et al.; International Subarachnoid Aneurysm Trial (ISAT) Collaborative Group. International Subarachnoid Aneurysm Trial (ISAT) of neurosurgical clipping versus endovascular coiling in 2143 patients with ruptured intracranial aneurysms: a randomised trial. Lancet 2002;360:1267-1274

35. Timsit C, Soize S, Benaissa A, Portefaix C, Gauvrit JY, Pierot L.
Contrast-enhanced and time-of-flight MRA at 3T compared with DSA for the follow-up of intracranial aneurysms treated with the WEB device. AJNR Am J Neuroradio/ 2016;37:1684-1689

36. Raoult $H$, Eugène F, Le Bras A, Mineur G, Carsin-Nicol B, Ferré $\mathrm{JC}$, et al. CT angiography for one-year follow-up of intracranial aneurysms treated with the WEB device: utility in evaluating aneurysm occlusion and WEB compression at one year. J Neuroradiol 2018;45:343-348

37. Arthur AS, Molyneux A, Coon AL, Saatci I, Szikora I, Baltacioglu F, et al.; WEB-IT Study investigators. The safety and effectiveness of the Woven EndoBridge (WEB) system for the treatment of wide-necked bifurcation aneurysms: final 12-month results of the pivotal WEB Intrasaccular Therapy (WEB-IT) study. J Neurointerv Surg 2019;11:924-930

38. Kabbasch C, Goertz L, Siebert E, Herzberg M, Hamisch C, Mpotsaris A, et al. Treatment strategies for recurrent and residual aneurysms after Woven Endobridge implantation. J Neurointerv Surg 2019;11:390-395

39. Pierot L, Bannery C, Batchinsky-Parrou V, Kleiber JC, Soize S, Litre CF. Clipping of recanalized intracerebral aneurysms initially treated by the Woven EndoBridge device. J Neurointerv Surg 2019;11:807-811

40. Cognard C, Januel AC. Remnants and recurrences after the use of the WEB intrasaccular device in large-neck bifurcation aneurysms. Neurosurgery 2015;76:522-530; discussion 530

41. Pierot L. Letter: WEB aneurysm treatment: occlusion stability and "compression". Neurosurgery 2015;77:E666-E667

42. Janot K, Herbreteau D, Amelot A, Charbonnier G, Boustia F, Narata AP, et al. Quantitative evaluation of WEB shape modification: a five-year follow-up study. J Neuroradio/ 2020;47:193-196

43. Herbreteau D, Bibi R, Narata AP, Janot K, Papagiannaki C, Soize $S$, et al. Are anatomic results influenced by WEB shape modification? Analysis in a prospective, single-center series of 39 patients with aneurysms treated with the WEB. AJNR Am J Neuroradio/ 2016;37:2280-2286

44. Caroff J, Cortese J, Girot JB, Mihalea C, Aguiar G, Vergara Martinez J, et al. Woven EndoBridge device shape modification can be mitigated with an appropriate oversizing strategy: a VasoCT based study. [published online ahead of print Mar 16, 2021] J Neurointerv Surg 2021

45. Rosskopf J, Braun M, Dreyhaupt J, Beer M, Schmitz BL, Ozpeynirci Y. Shape modification is common in Woven EndoBridge-treated intracranial aneurysms: a longitudinal quantitative analysis study. AJNR Am J Neuroradio/ 2020;41:1652-1656

46. White PM, Lewis SC, Nahser H, Sellar RJ, Goddard T, Gholkar A; HELPS Trial Collaboration. HydroCoil endovascular aneurysm 
occlusion and packing study (HELPS trial): procedural safety and operator-assessed efficacy results. AJNR Am J Neuroradiol 2008;29:217-223

47. Taschner CA, Chapot R, Costalat V, Machi P, Courthéoux P, Barreau $X$, et al. Second-generation hydrogel coils for the endovascular treatment of intracranial aneurysms: a randomized controlled trial. Stroke 2018;49:667-674

48. Piotin M, Blanc R, Spelle L, Mounayer C, Piantino R, Schmidt PJ, et al. Stent-assisted coiling of intracranial aneurysms: clinical and angiographic results in 216 consecutive aneurysms. Stroke 2010;41:110-115

49. McDougall CG, Johnston SC, Gholkar A, Barnwell SL, Vazquez Suarez JC, Massó Romero J, et al.; MAPS Investigators. Bioactive versus bare platinum coils in the treatment of intracranial aneurysms: the MAPS (Matrix and Platinum Science) trial. AJNR Am J Neuroradio/ 2014;35:935-942

50. Phan K, Huo YR, Jia F, Phan S, Rao PJ, Mobbs RJ, et al. Meta-analysis of stent-assisted coiling versus coiling-only for the treatment of intracranial aneurysms. J Clin Neurosci 2016;31:15-22
51. Becske T, Kallmes DF, Saatci I, McDougall CG, Szikora I, Lanzino G, et al. Pipeline for uncoilable or failed aneurysms: results from a multicenter clinical trial. Radiology 2013;267:858-868

52. Brinjikji W, Murad MH, Lanzino G, Cloft HJ, Kallmes DF. Endovascular treatment of intracranial aneurysms with flow diverters: a meta-analysis. Stroke 2013;44:442-447

53. Kallmes DF, Brinjikji W, Cekirge S, Fiorella D, Hanel RA, Jabbour $P$, et al. Safety and efficacy of the Pipeline embolization device for treatment of intracranial aneurysms: a pooled analysis of 3 large studies. J Neurosurg 2017;127:775-780

54. Pierot L, Spelle L, Berge J, Januel AC, Herbreteau D, Aggour M, et al. Feasibility, complications, morbidity, and mortality results at 6 months for aneurysm treatment with the flow re-direction endoluminal device: report of SAFE study. J Neurointerv Surg 2018;10:765-770

55. Pierot L, Spelle L, Berge J, Januel AC, Herbreteau D, Aggour M, et al. SAFE study (safety and efficacy analysis of FRED embolic device in aneurysm treatment): 1-year clinical and anatomical results. J Neurointerv Surg 2019;11:184-189 